\title{
BMJ
}

\section{Dietary calcium intake and risk of fracture and osteoporosis: prospective longitudinal cohort study}

\author{
Eva Warensjö, researcher, ${ }^{1,4}$ Liisa Byberg, researcher, ${ }^{1,4}$ Håkan Melhus, professor, ${ }^{3,4}$ Rolf Gedeborg, associate \\ professor, ${ }^{2,4}$ Hans Mallmin, professor, ${ }^{1}$ Alicja Wolk, professor, ${ }^{5}$ Karl Michaëlsson, professor ${ }^{1,4}$
}

${ }^{1}$ Department of Surgical Sciences, Section of Orthopaedics, Uppsala University, Uppsala, Sweden

${ }^{2}$ Department of Surgical Sciences, Anaesthesiology and Intensive Care, Uppsala University, Uppsala, Sweden

${ }^{3}$ Department of Medical Sciences, Clinical Pharmacology, Uppsala University, Uppsala, Sweden

${ }^{4}$ Uppsala Clinical Research Centre, UCR, Uppsala University, Uppsala, Sweden

${ }^{5}$ Division of Nutritional Epidemiology, Institute of Environmental Medicine, Karolinska Institutet, Stockholm, Sweden

Correspondence to: E Warensjö eva.warensjo@surgsci.uu.se

Cite this as: $B M J$ 2011;342:d1473 doi:10.1136/bmi.d1473

\section{ABSTRACT}

Objective To investigate associations between long term dietary intake of calcium and risk of fracture of any type, hip fractures, and osteoporosis.

Design A longitudinal and prospective cohort study, based on the Swedish Mammography Cohort, including a subcohort, the Swedish Mammography Cohort Clinical. Setting A population based cohort in Sweden established in 1987.

Participants 61433 women (born between 1914 and 1948) were followed up for 19 years. 5022 of these women participated in the subcohort.

Main outcome measures Primary outcome measures were incident fractures of any type and hip fractures, which were identified from registry data. Secondary outcome was osteoporosis diagnosed by dual energy $x$ ray absorptiometry in the subcohort. Diet was assessed by repeated food frequency questionnaires.

Results During follow-up, 14738 women (24\%) experienced a first fracture of any type and among them $3871(6 \%)$ a first hip fracture. Of the 5022 women in the subcohort, 1012 (20\%) were measured as osteoporotic. The risk patterns with dietary calcium were non-linear. The crude rate of a first fracture of any type was 17.2/1000 person years at risk in the lowest quintile of calcium intake, and 14.0/1000 person years at risk in the third quintile, corresponding to a multivariable adjusted hazard ratio of 1.18 (95\% confidence interval 1.12 to 1.25). The hazard ratio for a first hip fracture was 1.29 (1.17 to 1.43$)$ and the odds ratio for osteoporosis was 1.47 (1.09 to 2.00). With a low vitamin D intake, the rate of fracture in the first calcium quintile was more pronounced. The highest quintile of calcium intake did not further reduce the risk of fractures of any type, or of osteoporosis, but was associated with a higher rate of hip fracture, hazard ratio 1.19 (1.06 to 1.32).

Conclusion Gradual increases in dietary calcium intake above the first quintile in our female population were not associated with further reductions in fracture risk or osteoporosis.

\section{INTRODUCTION}

Osteoporotic fractures are frequent in elderly populations, especially in women, and are associated with high healthcare costs and individual suffering. With ageing populations, the burden of osteoporotic fractures on society will increase in the coming years ${ }^{1}$ and the prevention of osteoporotic fractures is therefore a major public health issue. The importance and optimal level of calcium intake to compensate for skeletal calcium losses ${ }^{1}$ and for the prevention of osteoporosis and fractures have been much debated and remain unclear. This is reflected by the wide range of daily calcium recommendations for individuals older than 50 years: at present $700 \mathrm{mg}$ in the $\mathrm{UK},{ }^{2} 800 \mathrm{mg}$ in Scandinavia, ${ }^{3} 1200 \mathrm{mg}$ in the United States, ${ }^{4}$ and $1300 \mathrm{mg}$ in Australia and New Zealand. ${ }^{5}$

It is problematic to make recommendations regarding calcium intake based on the results from clinical trials and previous cohort studies. Meta-analyses of randomised trials found that supplemental calcium gave modest $^{6}$ or no reduction ${ }^{7}$ in risk of fracture. Both the habitual dietary intake of calcium and vitamin D status may affect the outcome and are rarely accounted for in the design of calcium supplementation trials. ${ }^{8}$ Nor do observational data provide clear evidence, as emphasised by meta-analyses with differing results, on the association between calcium intake and fracture risk. ${ }^{910}$ To improve precision, prospective studies with repeated dietary surveys and large numbers of participants are needed.

Against this background, we aimed to investigate associations between long term dietary intake of calcium with risk of fracture of any type, with hip fractures, and with osteoporosis, in a large, population based prospective study of Swedish women.

\section{METHODS}

The Swedish Mammography Cohort

The Swedish Mammography Cohort was established in 1987-1990. All 90303 women residing in two Swedish counties (Uppsala and Västmanland) and born between 1914 and 1948 received a mailed invitation to a routine mammography screening. Enclosed with this invitation was a questionnaire covering diet (food frequency questionnaire) and lifestyle, which was completed by $74 \%$ of the women. In 1997 a second expanded questionnaire was sent to those who were still living in the study area (response rate 70\%). The study sample with exclusions has been described 
previously ${ }^{11}$ and 61433 women with baseline data and 38984 with data from 1997 were available for analysis in the present fracture study (fig 1).

\section{Fracture identification}

Fracture events were collated through linkage to the Swedish National Patient Registry. ${ }^{12}$ Data on outpatient treated fractures were identified from outpatient registers. An almost complete (99.7\%) deterministic record linkage was enabled by use of the unique identification number assigned to all Swedish permanent residents. Any fracture event was defined as a hospital admission or an outpatient visit with an International Classification of Diseases (ICD10) diagnosis code of S12, S22, S32, S42, S52, S62, S72, S82, or S92. Hip fracture cases were defined by the codes S720, S721, and S722. Incident fracture admissions were separated from readmissions from a previous fracture event by the use of a previously validated and accurate method. ${ }^{13}$

\section{The Swedish Mammography Cohort Clinical (SMCC)}

Between November 2003 and October 2009, we invited a randomly selected subcohort of the Swedish Mammography Cohort living in the city of Uppsala to undergo dual energy $\mathrm{x}$ ray absorptiometry (DXA, Lunar Prodigy, Lunar corp, Madison, WI, USA) measurements, to provide blood and urine samples, and to have height and weight measurements taken. A third questionnaire on diet and lifestyle factors (similar to

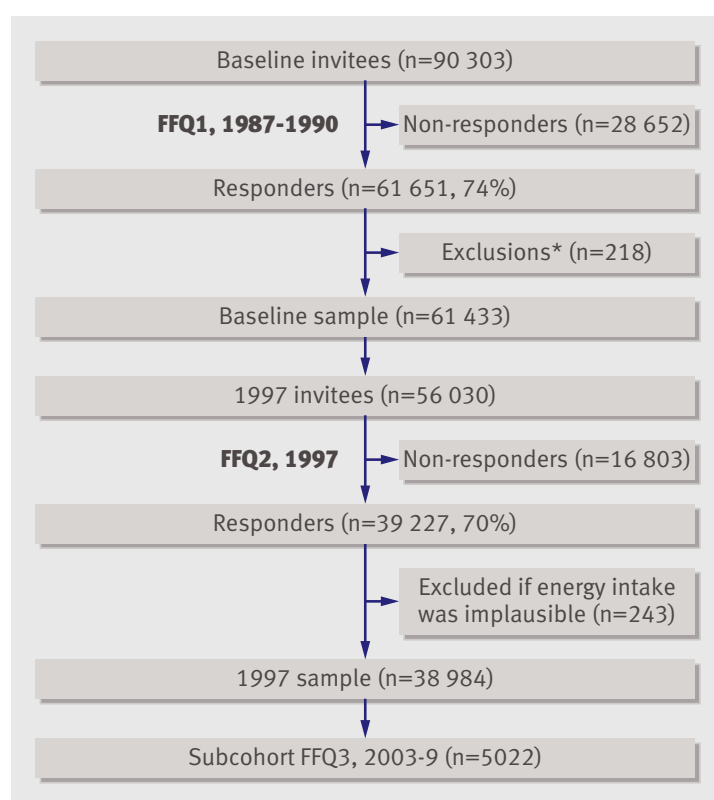

Fig $1 \|$ The flow chart depicts the study samples in the Swedish Mammography Cohort. *Excluded were those with an erroneous personal identification number, questionnaires that was not dated, erroneous dates of moving out of the study area or death, implausible energy intakes $( \pm 3$ SD from the mean value of the log transformed reported energy intake), and a cancer diagnosis (except non-melanoma skin cancer) before baseline. ${ }^{11} \mathrm{FFQ}=$ food frequency questionnaire the 1997 food frequency questionnaire) was also completed before the clinical examination. The participation rate was $65 \%$ and the subcohort included 5022 women (fig 1). Bone mineral density $\left(\mathrm{BMD}, \mathrm{g} / \mathrm{cm}^{2}\right)$ was determined at the hip, at the lumbar spine (L1L4), and of the total body. Osteoporosis was defined as a T-score at either the total hip, femoral neck, or spine of $\leq 2.5$ standard deviations (SD) below the mean of a young adult reference range. ${ }^{14}$ The precision error of the bone mineral density measurements, based on triple measurements in 15 participants, varied depending on sites between $0.8 \%$ and $1.5 \%$. Daily scans of a lumbar spine phantom were performed. The long term coefficient of variation was less than $1 \%{ }^{15}$

The present study was therefore made up of two study samples: the Swedish Mammography Cohort with the primary outcomes of any fracture and hip fracture, and the subcohort Swedish Mammography Cohort Clinical with the secondary outcome of osteoporosis.

\section{Dietary assessment}

The food frequency questionnaires have been described previously. ${ }^{111617}$ Nutrient intakes were estimated by multiplying the frequency of consumption of each food item by the nutrient content of age specific portion sizes. Nutrient data were obtained from the Swedish National Food Administration database. ${ }^{18}$ Nutrient intakes were adjusted for total energy intake (mean 1700 kilocalories in the study population) using the residual method. ${ }^{19}$ To better account for changes in diet during follow-up and to better represent long term dietary intake, calcium intake was treated as cumulative average intake. ${ }^{20}$ In the second and third food frequency questionnaires (the 1997 expanded questionnaire and the questionnaire completed by the SMCC subcohort) the lifetime use of dietary supplements and multivitamins was reported. One calcium dose was considered to be $500 \mathrm{mg}$ if from calcium supplements and $120 \mathrm{mg}$ if from multivitamins. Total calcium intake included supplemental calcium. Reported frequency of calcium supplement use (with or without vitamin D) within the cohort during the first years of follow-up was low $(6 \%),{ }^{21}$ and this proportion was similar for women with low and high dietary calcium intake. Both dietary and total calcium intake in the 1997 food frequency questionnaire correlated well with estimates from 14 repeated 24 hour recalls over one year $(\mathrm{r}=0.77) .{ }^{22}$ A second validation of calcium intake was carried out with 7 day food records, which were assessed on four occasions, every third month, in 104 of the women $(\mathrm{r}=0.72)$. Bland-Altman plots showed only small systematic errors related to intake level between the methods. The average difference between 1997 food frequency questionnaire and food records was -56.4 (95\% confidence interval -4.4 to 108.4). It has been observed previously ${ }^{22}$ that the food frequency method gives higher estimates of calcium intake. Similar estimates were obtained for the baseline questionnaire. ${ }^{21}$ 
Table 1 |Characteristics of participants by quintiles of average cumulative intake* of calcium

\begin{tabular}{|c|c|c|c|c|c|}
\hline & \multicolumn{5}{|c|}{ Quintile } \\
\hline & 1 & 2 & 3 & 4 & 5 \\
\hline Calcium intake $(\mathrm{mg})^{*}$ & $<751$ & 751-882 & 882-996 & $996-1137$ & $\$ 1137$ \\
\hline \multicolumn{6}{|l|}{ Entire cohort } \\
\hline Age (years) at entry & $54.4(10.0)$ & $53.8(9.8)$ & $53.5(9.7)$ & $53.3(9.6)$ & $53.6(9.6)$ \\
\hline BMl at entry $\left(\mathrm{kg} / \mathrm{m}^{2}\right)$ & $24.7(4.1)$ & $24.6(4.0)$ & $24.7(3.8)$ & $24.7(3.9)$ & $25.0(4.0)$ \\
\hline \multicolumn{6}{|l|}{ Average intake per day $\dagger$} \\
\hline Energy (kcal) & $1600(518)$ & $1662(452)$ & $1659(435)$ & $1640(426)$ & $1568(431)$ \\
\hline Calcium (mg) & $603(241)$ & $810(228)$ & $922(253)$ & $1028(276)$ & $1194(356)$ \\
\hline Supplemental calcium $(\mathrm{mg}) \ddagger$, $\S$ & $322(466)$ & $255(350)$ & $248(345)$ & $245(344)$ & $245(336)$ \\
\hline Total calcium (mg) & $641(313)$ & $850(292)$ & $966(314)$ & $1075(336)$ & $1239(404)$ \\
\hline Vitamin D $(\mu \mathrm{g})$ & $4.1(1.3)$ & $4.3(1.2)$ & $4.4(1.2)$ & $4.5(1.3)$ & $4.9(1.4)$ \\
\hline Retinol $(\mu \mathrm{g})$ & $941(642)$ & $963(576)$ & $974(569)$ & $991(565)$ & $1041(556)$ \\
\hline Potassium (mg) & $2.9(0.47)$ & $3.0(0.42)$ & $3.1(0.42)$ & $3.2(0.42)$ & $3.3(0.48)$ \\
\hline Protein (g) & $59.7(8.0)$ & $64.7(6.7)$ & $67.7(6.4)$ & $70.8(6.2)$ & $76.2(7.1)$ \\
\hline Alcohol (g) & $3.1(4.5)$ & $3.2(4.1)$ & $3.0(3.7)$ & $2.8(3.4)$ & $2.6(3.2)$ \\
\hline Coffee (g) & $481(226)$ & $487(216)$ & $495(213)$ & $502(215)$ & $512(225)$ \\
\hline Nulliparity n (\%) & $1525(12.4)$ & $1249(10.2)$ & $1224(10.0)$ & $1211(9.9)$ & $1314(10.7)$ \\
\hline \multicolumn{6}{|l|}{ Leisure time PA level n (\%)§ } \\
\hline 1 (lowest) & $1243(23.7)$ & $1401(20.3)$ & $1412(18.8)$ & $1453(19.0)$ & $1382(19.0)$ \\
\hline 2 & $1221(23.3)$ & $1690(24.5)$ & $1791(23.8)$ & $1770(23.1)$ & $1678(23.0)$ \\
\hline 3 & $1617(30.8)$ & $2258(32.8)$ & $2596(34.5)$ & $2621(34.3)$ & $2513(34.5)$ \\
\hline 4 & $575(10.9)$ & $794(11.5)$ & $893(11.9)$ & $984(12.8)$ & $847(11.5)$ \\
\hline 5 (highest) & $593(11.3)$ & $752(10.9)$ & $830(11.0)$ & $823(10.8)$ & $872(12.0)$ \\
\hline \multicolumn{6}{|l|}{ Smoking status $\mathrm{n}(\%) \S$} \\
\hline Yes & $1514(25.7)$ & $1699(22.4)$ & $1749(21.3)$ & $1855(22.2)$ & $2014(25.0)$ \\
\hline No & $3026(51.3)$ & $4186(55.2)$ & $4646(56.4)$ & $4574(54.6)$ & $4152(51.5)$ \\
\hline Former & $1356(23.0)$ & $1699(22.4)$ & $1838(22.3)$ & $1943(23.2)$ & $1892(23.5)$ \\
\hline Two or more Charlson's comorbidities ${ }^{23}(\%)$ & $1693(13.8)$ & $1415(11.5)$ & $1398(11.4)$ & $1376(11.2)$ & $1424(11.6)$ \\
\hline \multicolumn{6}{|l|}{ Educational level } \\
\hline $10-12$ years & $830(6.8)$ & $815(6.7)$ & $842(6.9)$ & $893(7.3)$ & $807(6.6)$ \\
\hline$>12$ years & $953(7.9)$ & $1431(11.8)$ & $1510(12.4)$ & $1657(13.6)$ & $1600(13.2)$ \\
\hline Other & $459(3.8)$ & $394(3.2)$ & $356(2.9)$ & $323(2.7)$ & $341(2.8)$ \\
\hline \multicolumn{6}{|l|}{ Subcohort } \\
\hline Age at investigation & $66.4(6.2)$ & $67.2(6.7)$ & $67.7(6.7)$ & $67.6(6.8)$ & $68.1(6.9)$ \\
\hline $\mathrm{BMI}\left(\mathrm{kg} / \mathrm{m}^{2}\right)$ & $25.8(4.6)$ & $25.7(4.0)$ & $25.8(4.3)$ & $26.0(4.3)$ & $26.3(4.4)$ \\
\hline \multicolumn{6}{|l|}{ Intake per day** } \\
\hline Energy (kcal) & $1716(612)$ & $1827(563)$ & $1790(524)$ & $1808(513)$ & $1767(530)$ \\
\hline Calcium (mg) & $698(156)$ & $888(161)$ & $996(165)$ & $1116(190)$ & $1389(297)$ \\
\hline Supplemental calcium(mg)†† & $422(155)$ & $359(188)$ & $351(188)$ & $356(185)$ & $388(177)$ \\
\hline Total calcium (mg) & $748(211)$ & $932(214)$ & $1036(215)$ & $1160(233)$ & $1438(329)$ \\
\hline Vitamin D $(\mu \mathrm{g})$ & $5.4(2.0)$ & $5.5(1.9)$ & $5.5(1.6)$ & $5.6(1.7)$ & $5.9(2.0)$ \\
\hline Retinol $(\mu \mathrm{g})$ & $773(606)$ & $760(592)$ & $759(511)$ & $760(445)$ & $798(433)$ \\
\hline Potassium (mg) & $3.1(0.55)$ & $3.3(0.53)$ & $3.3(0.49)$ & $3.3(0.52)$ & $3.4(0.56)$ \\
\hline Protein (g) & $61.4(7.6)$ & $64.9(6.1)$ & $68.0(5.9)$ & $71.2(5.9)$ & $76.4(6.6)$ \\
\hline Alcohol (g) & $8.2(8.4)$ & $7.4(6.8)$ & $7.1(7.2)$ & $6.2(5.8)$ & $5.9(6.6)$ \\
\hline Coffee (g) & $428(291)$ & $430(248)$ & 446 (245) & $471(264)$ & $498(282)$ \\
\hline
\end{tabular}

Data shown is mean (SD) or $\mathrm{n}(\%)$ where indicated.

$\mathrm{PA}=$ physical activity, $\mathrm{BMI}=$ body mass index.

*Calcium intake by quintiles refers to the cumulative energy adjusted average dietary intake in the entire cohort.

†Energy adjusted average nutrient data was estimated with data from the baseline and the 1997 questionnaire.

$\ddagger$ Supplemental calcium (alone or in combination with vitamin D) was used by 10<thin〉055 participants.

§Information only available in the 1997 questionnaire.

đEducational level "other" refers to vocational or other education.

$\star \star$ Intake per day refers to the energy adjusted intake in the subcohort.

††Supplemental calcium was used by 610 participants. 
Table 2 |Rate of any fracture, hip fracture, and osteoporosis by quintiles of average cumulative intake* of dietary calcium in the entire cohort, and the subcohort (SMCC)

\begin{tabular}{|c|c|c|c|c|c|c|}
\hline & \multicolumn{5}{|c|}{ Quintile } & \multirow[b]{2}{*}{ Per 300 mg calcium } \\
\hline & 1 & 2 & 3 & 4 & 5 & \\
\hline Calcium intake $(\mathrm{mg})^{*}$ & $<751$ & $751-882$ & $882-996$ & $996-1137$ & $>1137$ & - \\
\hline \multicolumn{7}{|l|}{ First event any fracture } \\
\hline Number of fractures & 3243 & 2941 & 2841 & 2872 & 2841 & 14738 \\
\hline Person-years at risk & 188850 & 199411 & 202680 & 203216 & 202656 & - \\
\hline Rate per 1000 person years & 17.2 (16.6 to 17.8$)$ & $14.7(14.2$ to 15.3$)$ & $14.0(13.5$ to 14.5$)$ & 14.1 (13.6 to 14.7$)$ & $14.0(13.5$ to 14.5$)$ & - \\
\hline Age-adjusted HR $(95 \% \mathrm{Cl}) \dagger$ & 1.25 (1.19 to 1.32$)$ & $1.06(1.00$ to 1.11$)$ & 1.0 (Reference) & $1.00(0.96$ to 1.06$)$ & $1.00(0.95$ to 1.06$)$ & $0.92(0.90$ to 0.93$)$ \\
\hline Adjusted HR $(95 \% \mathrm{Cl}) \dagger$ & 1.18 (1.12 to 1.25$)$ & 1.04 (0.98 to 1.10$)$ & 1.0 (Reference) & $1.02(0.96$ to 1.07$)$ & $1.00(0.95$ to 1.06$)$ & $0.94(0.92$ to 0.96$)$ \\
\hline \multicolumn{7}{|l|}{ Multiple event any fracture } \\
\hline Number of fractures & 5277 & 4628 & 4437 & 4579 & 4592 & 23513 \\
\hline Person-years at risk & 192473 & 202346 & 205336 & 205883 & 205517 & - \\
\hline Rate per 1000 person years & 27.4 (26.7 to 28.2$)$ & $22.8(22.2$ to 23.5$)$ & 21.6 (21.0 to 22.3$)$ & 22.2 (21.6 to 22.9) & 22.3 (21.7 to 23.0$)$ & - \\
\hline Age-adjusted HR $(95 \% \mathrm{Cl}) \dagger$ & 1.14 (1.08 to 1.19$)$ & $1.03(0.98$ to 1.08$)$ & 1.0 (Reference) & $1.03(0.98$ to 1.08$)$ & $1.01(0.96$ to 1.06$)$ & $0.96(0.94$ to 0.98$)$ \\
\hline Adjusted HR $(95 \% \mathrm{Cl}) \dagger$ & $1.10(1.05$ to 1.16$)$ & 1.03 (0.98 to 1.08$)$ & 1.0 (Reference) & 1.03 (0.98 to 1.09$)$ & 1.01 (0.96 to 1.07$)$ & 0.97 (0.95 to 0.99) \\
\hline \multicolumn{7}{|l|}{ First event hip fracture } \\
\hline Number of fractures & 956 & 751 & 680 & 730 & 754 & 3871 \\
\hline Person-years at risk & 205895 & 214001 & 217223 & 217228 & 215638 & - \\
\hline Rate per 1000 person years & $4.6(4.4$ to 4.9$)$ & 3.5 (3.3 to 3.8$)$ & $3.1(2.9$ to 3.4$)$ & $3.4(3.1$ to 3.6$)$ & 3.5 (3.3 to 3.8) & - \\
\hline Age-adjusted HR(95\% Cl)† & 1.51 (1.37 to 1.67$)$ & $1.13(1.01$ to 1.24$)$ & 1.0 (Reference) & $1.07(0.97$ to 1.19$)$ & $1.12(1.01$ to 1.24$)$ & 0.88 (0.85 to 0.92$)$ \\
\hline Adjusted HR $(95 \% \mathrm{Cl}) \dagger$ & $1.29(1.17$ to 1.43$)$ & $1.09(0.98$ to 1.21$)$ & 1.0 (Reference) & $1.13(1.01$ to 1.26$)$ & 1.19 (1.06 to 1.32$)$ & $0.96(0.92$ to 1.00$)$ \\
\hline \multicolumn{7}{|l|}{ Multiple event hip fracture } \\
\hline Number of fractures & 1457 & 1175 & 1045 & 1116 & 1159 & 5952 \\
\hline Person-years at risk & 206332 & 214458 & 217521 & 217567 & 215994 & - \\
\hline Rate per 1000 person years & $7.1(6.7$ to 7.4$)$ & $5.5(5.2$ to 5.8$)$ & $4.8(4.5$ to 5.1$)$ & $5.1(4.8$ to 5.4$)$ & $5.4(5.1$ to 5.7$)$ & - \\
\hline Age-adjusted HR(95\% Cl)† & 1.30 (1.18 to 1.44$)$ & $1.02(0.92$ to 1.44$)$ & 1.0 (Reference) & $1.04(0.94$ to 1.15$)$ & $1.09(0.98$ to 1.20$)$ & $0.92(0.89$ to 0.97$)$ \\
\hline Adjusted HR $(95 \% \mathrm{Cl}) \dagger$ & $1.20(1.05$ to 1.37$)$ & 1.01 (0.88 to 1.15$)$ & 1.0 (Reference) & $1.00(0.87$ to 1.15$)$ & 1.12 (0.98 to 1.28$)$ & $0.96(0.91$ to 1.01$)$ \\
\hline \multicolumn{7}{|l|}{ SMCC osteoporosis } \\
\hline Number of women with osteoporosis (\%) & $93(23.7 \%)$ & $191(22.2 \%)$ & $230(19.8 \%)$ & $243(18.5 \%)$ & 255 (19.7\%) & $1012(20.2 \%)$ \\
\hline Number of women without osteoporosis & 300 & 669 & 930 & 1072 & 1039 & 4010 \\
\hline Age-adjusted OR $(95 \% \mathrm{CI}) \ddagger$ & 1.44 (1.08 to 1.90$)$ & $1.22(0.98$ to 1.53$)$ & 1.0 (Reference) & $0.91(0.75$ to 1.13$)$ & $0.96(0.78$ to 1.18$)$ & $0.89(0.80$ to 0.99$)$ \\
\hline Adjusted OR $(95 \% \mathrm{Cl}) \ddagger$ & 1.47 (1.09 to 2.00$)$ & $1.26(0.99$ to 1.60$)$ & 1.0 (Reference) & $0.92(0.74$ to 1.15$)$ & $1.01(0.81$ to 1.27$)$ & $0.84(0.75$ to 0.95$)$ \\
\hline \multicolumn{7}{|c|}{ 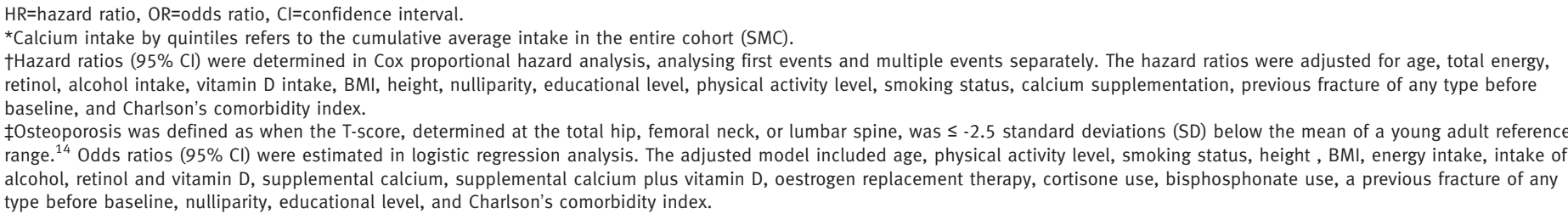 } \\
\hline
\end{tabular}

\section{Additional information}

Lifestyle information was obtained from the questionnaires. This included the use of postmenopausal oestrogen therapy and menopausal status, parity information, weight and height, smoking habits, and leisure time physical activity during the past year (with five pre-defined levels ranging from 1 hour per week to more than 5 hours per week). Physical activity collected in the 1997 questionnaire is valid compared with activity records and accelerometer data. ${ }^{23}$ The educational level was determined with four categories: less than or equal to 9 years, 10 to 12 years, more than 12 years, and other education such as vocational.

ICD diagnosis codes were collated from the Swedish National Patient Registry (versions 8, 9, and 10) to calculate Charlson's comorbidity index. ${ }^{2425}$

\section{Statistical analysis}

For each participant follow-up time was accrued from baseline (1987-1990) until the date of fracture, date of death, date of leaving the study regions, or the end of the study period (31 December 2008). We estimated age adjusted and multivariable adjusted hazard ratios by Cox proportional hazards regression and odds ratios by logistic regression. We examined the relationship between quintiles of cumulative dietary calcium intake and risk of fracture and osteoporosis. For comparison with previous studies ${ }^{7}$ we also examined the effect of each $300 \mathrm{mg}$ per day increment of calcium. In order to facilitate comparisons of the estimates the quintile cutoffs were defined in the entire Swedish Mammography Cohort, despite a higher average calcium intake in the subcohort. In a supplementary 
Table $3 \mid$ Adjusted hazard ratio (95\% confidence interval) of any fractures and hip fractures by quintiles of total calcium intake (including supplements) and calibrated calcium intake in the entire cohort

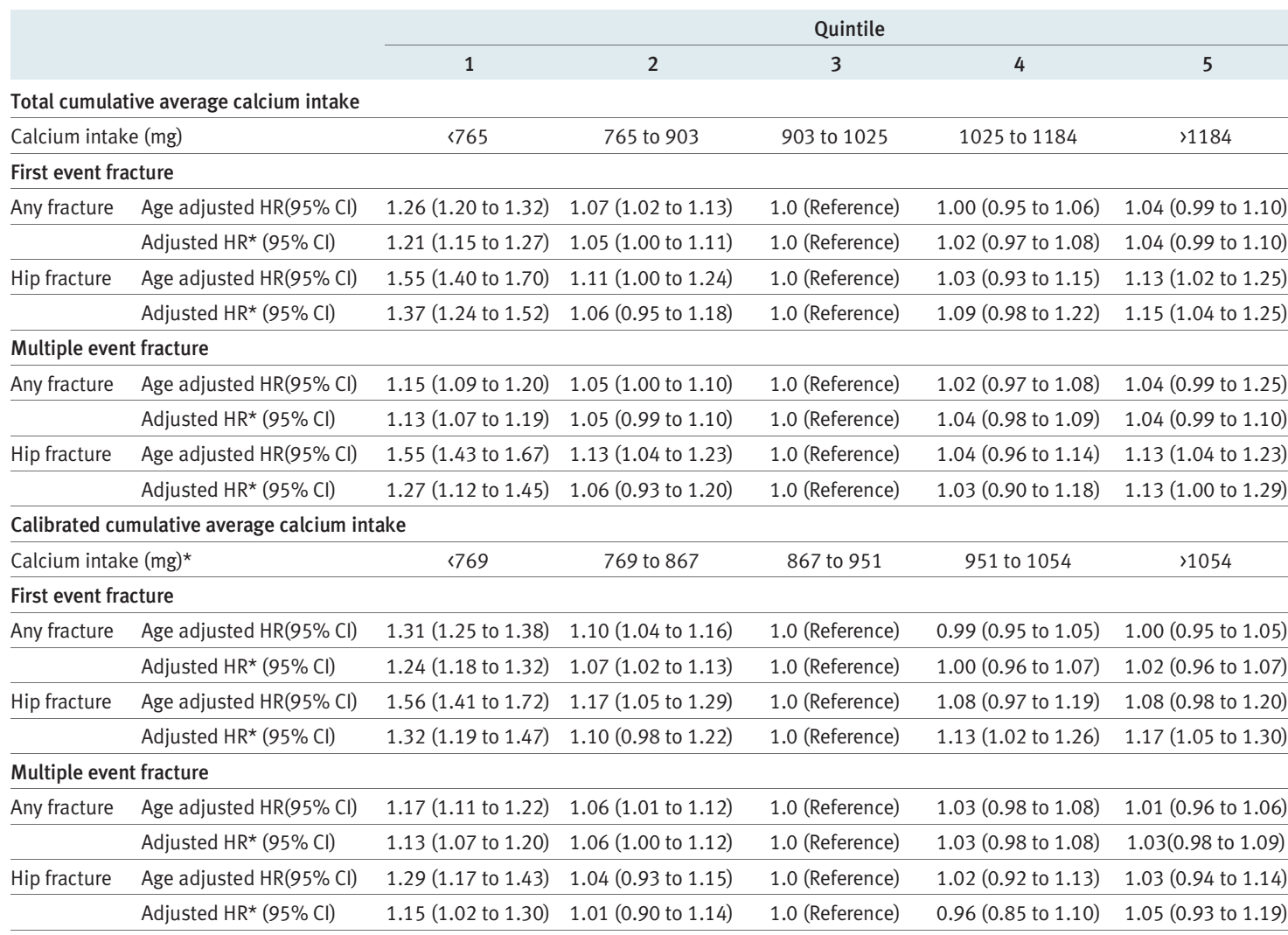

$\mathrm{HR}=$ hazard ratio, $\mathrm{Cl}=$ confidence interval.

*Hazard ratios ( $95 \%$ confidence interval) were determined in Cox proportional hazard analysis. The hazard ratios were adjusted for age, total energy, retinol, alcohol intake, vitamin D intake, BMI, height, nulliparity, educational level, physical activity level, smoking status, previous fracture of any type before baseline, and Charlson's comorbidity index. Calcium supplementation was only included in the model with the calibrated calcium intake.

analysis we analysed multiple fractures by calcium intake in a conditional risk set model for Cox regression. ${ }^{26}$ We also re-ran our main analyses by use of total calcium intake and with a calibrated food frequency questionnaire calcium intake obtained by use of linear regression coefficients between food records $(\mathrm{FR})$ and food frequency questionnaire (FFQ) $\left(\mathrm{R}_{i \mathrm{FR}}=\right.$ $\alpha_{\mathrm{FR}}+\beta_{\mathrm{FR}} * \mathrm{FFQ} i$ ( $\mathrm{R}$ reported calcium in $\mathrm{FR}, i$ individual)). ${ }^{27}$ The proportional hazard assumptions in the Cox models were confirmed graphically by comparing Nelson-Aalen plots with Schoenfeld's test. Non-linear trends of hip fracture risk were additionally analysed using restricted cubic spline Cox regression. We used four knots placed at percentiles 5, 35, 65, and 95 of the cumulative average calcium intake. ${ }^{28}$ The reference level was set to $800 \mathrm{mg}$ of calcium, which corresponds to the recommended daily intake for Swedish women older than 50 years. ${ }^{3}$

In the analysis of fractures in the full cohort, the multivariable models included age, total energy, intake of retinol, alcohol, and vitamin $\mathrm{D}$, body mass index, height (all continuous), educational level ( $\leq 9$ years, 10-12 years, $>12$ years, other), nulliparity (yes or no), calcium supplement use (yes or no), physical activity (five categories), smoking status (never, former, current), fracture of any type before baseline (yes or no), and Charlson's comorbidity index (continuous, 1 to 16). ${ }^{2425}$ Other potential covariates such as menopausal status, potassium intake, protein intake, and coffee consumption in the multivariable models only marginally changed the relations and were not included in the model. Covariates were treated as time dependent variables. Covariates not assessed in the baseline food frequency questionnaire (such as smoking habits and physical activity) were imputed by the Markov chain Monte Carlo multiple imputation method. Sensitivity analysis with restriction to non-missing data did not alter our interpretation of the results. In the clinical subcohort with osteoporosis as the outcome, covariates related to medication (use or non-use of supplemental calcium and vitamin $\mathrm{D}$, oestrogen replacement therapy, cortisone, or bisphosphonates) were additionally included in the multivariable model.

Effect measure modification between dietary calcium and vitamin D intake was investigated by including a product interaction term in multivariable models and performing likelihood ratio tests of its contribution in nested models. Stratified analyses were thereafter performed by the median cut-off value $4.4 \mu \mathrm{g} /$ day of dietary vitamin $\mathrm{D}$ intake.

Given that calcium supplementation in a recent meta-analysis of randomised trials increased 
cardiovascular disease events ${ }^{29}$ and also given that cardiovascular disease is associated with an increased risk of fracture ${ }^{30}$ we considered the potential competing risk problem from mortality by the method of Fine and Gray $^{31}$ and by cumulative incidence curves. ${ }^{32}$ The sub hazard ratios were similar to the hazard ratios from the ordinary Cox regression (data not shown), suggesting no effect of competing risks.

The statistical analysis was performed with STATA release 11 (StataCorp, College Station, Texas, USA) and SAS version 9.2 (SAS Institute, Cary, NC, USA).

\section{RESULTS}

Table 1 shows the characteristics of the study participants by quintiles of dietary calcium intake. With increasing quintiles of calcium intake the reported intake for most other nutrients also increased. Small differences were present for calcium supplement use, comorbidity, educational level, smoking status, and physical activity level between quintiles.

During a median of 19.2 years of follow-up and 996800 person years at risk, 14738 women $(24 \%)$ experienced any type of first fracture and $5043(8 \%)$ experienced two or more fractures. For hip fractures the corresponding numbers were $3871(6 \%)$ and 1368 $(2 \%)$ during a median of 19.8 years of follow-up and 1069980 person years at risk. In the subcohort, 1012 $(20 \%)$ of the participants were classified as osteoporotic.

There was an apparent decrease in risk for every $300 \mathrm{mg}$ increase of dietary calcium intake (table 2) but the associations were non-linear $(\mathrm{P}<0.001$ for calcium intake as a quadratic term). The rate of first fractures and prevalence of osteoporosis were highest in the lowest quintile of dietary calcium intake (table 2). Within this quintile, compared with the third (table 2),

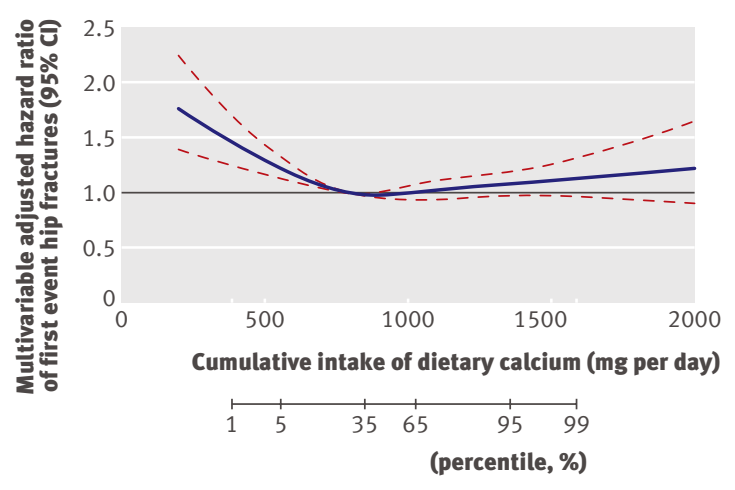

Fig 2 || Multivariable adjusted spline curve for relation between cumulative average intake of dietary calcium and time to first hip fracture. Multivariable adjusted hazard ratio indicated by solid line and $95 \%$ confidence interval by dashed lines. Models were adjusted for age, total energy, retinol, alcohol intake, vitamin D intake, BMI, height, nulliparity, educational level, physical activity level, smoking status, calcium supplementation, previous fractures, and Charlson's comorbidity index. Asterisks on $\mathrm{x}$ axis correspond to first $(387 \mathrm{mg})$ and 99 th $(1591 \mathrm{mg})$ percentile of the cumulative intake of calcium. Reference value for estimation set at $800 \mathrm{mg}$, which corresponds to Swedish recommended level of calcium intake for women older than 50 years ${ }^{3}$ the multivariable adjusted hazard ratio for any fracture was 1.18 (95\% confidence interval 1.12 to 1.25) and for hip fracture 1.29 (1.17 to 1.43 ). These estimates were somewhat weaker when we analysed multiple fracture events (table 2). Within the lowest quintile, the risk of fracture increased for every $100 \mathrm{mg}$ decrease in calcium intake, with a multivariable adjusted hazard ratio of 1.08 (1.04 to 1.11) for any first fracture and 1.07 (1.01 to 1.13 ) for first hip fracture $(\mathrm{P}=0.19$ and $\mathrm{P}=0.32$, respectively, for the quadratic term of calcium intake). The lowest quintile of dietary calcium intake was also associated with an increased risk of osteoporosis (adjusted odds ratio 1.47, 95\% confidence interval 1.09 to 2.00$)$.

In the highest quintile of calcium intake, the rate of fracture of any type and the rate of osteoporosis were similar to those in the third quintile (table 2), whereas the hip fracture rate was raised in the highest quintile (hazard ratio $1.19,95 \%$ confidence interval 1.06 to 1.32). The non-linear association between dietary calcium intake and first hip fracture rate is further illustrated by the spline curve in fig 2 . Neither quintiles of total calcium intake (including supplements) nor the use of calibrated dietary calcium intake essentially changed the estimated hazard ratios for fracture, although the higher fracture rate at low intake levels became more pronounced (table 3). The results also remained essentially unchanged after exclusion of women with a previous fracture of any type before the hip fracture event after baseline, or when the analysis was restricted to specific age intervals $(<70,70-80$, $>80$ years).

Vitamin D intake modified the associations between calcium intake and the rate of fractures of any type $\left(\mathrm{P}_{\text {interaction }}=0.01\right)$ and at the hip $\left(\mathrm{P}_{\text {interaction }}=0.02\right)$, but not the odds of osteoporosis. Although the association between dietary calcium intake and fracture rate was similar both with a vitamin D intake below and above the median, there was a tendency towards a higher hip fracture rate within the lowest quintile of dietary calcium intake in combination with a low dietary vitamin D intake (table 4 ).

\section{DISCUSSION}

Principal findings

These findings show an association between a low habitual dietary calcium intake (lowest quintile) and an increased risk of fractures and of osteoporosis. Above this base level, we observed only minor differences in risk. The rate of hip fracture was even increased in those with high dietary calcium intakes.

\section{Strengths and weaknesses of the study}

Strengths of our study include the population based prospective design with both fractures and osteoporosis as outcomes, and repeated measurements of calcium intake, together with a large number of potential covariates. Incident fractures were traced though national healthcare registries and deterministic record linkage, permitting almost complete case ascertainment. We have adjusted for several important 
Table $4 \mid$ Adjusted hazard ratio ( $95 \%$ confidence interval) of any fractures and hip fractures by quintiles of cumulative average calcium intake in the entire cohort, stratified by reported dietary intake of vitamin $D$

\begin{tabular}{|c|c|c|c|c|c|c|}
\hline & \multicolumn{5}{|c|}{ Quintile } & \multirow{2}{*}{$\begin{array}{l}\text { Per } 300 \mathrm{mg} \\
\text { calcium }\end{array}$} \\
\hline & 1 & 2 & 3 & 4 & 5 & \\
\hline Calcium intake (mg) & $<751$ & 751 to 882 & 882 to 996 & 996 to 1137 & $>1137$ & - \\
\hline \multicolumn{7}{|l|}{ First event any fracture } \\
\hline \multicolumn{7}{|l|}{ Low† vitamin D intake } \\
\hline Adjusted HR $¥(95 \% \mathrm{Cl})$ & 1.21 (1.13 to 1.30$)$ & 1.07 (1.00 to 1.15$)$ & 1.0 (Reference) & 1.05 (0.97 to 1.14$)$ & 0.98 (0.90 to 1.07$)$ & 0.91 (0.88 to 0.94$)$ \\
\hline \multicolumn{7}{|l|}{ High† vitamin D intake } \\
\hline Adjusted HR $\ddagger(95 \% \mathrm{Cl})$ & 1.16 (1.07 to 1.26$)$ & $1.00(0.92$ to 1.08$)$ & 1.0 (Reference) & 0.98 (0.91 to 1.06$)$ & $0.99(0.92$ to 1.06$)$ & 0.95 (0.93 to 0.98$)$ \\
\hline \multicolumn{7}{|l|}{ First event hip fracture } \\
\hline \multicolumn{7}{|l|}{ Low† vitamin D intake } \\
\hline Adjusted HR $\ddagger(95 \%$ Cl) & 1.39 (1.21 to 1.59$)$ & 1.09 (0.94 to 1.27$)$ & 1.0 (Reference) & 1.09 (0.93 to 1.28$)$ & 1.20 (1.01 to 1.43$)$ & 0.92 (0.85 to 0.97$)$ \\
\hline \multicolumn{7}{|l|}{ High† vitamin D intake } \\
\hline Adjusted HR $\ddagger(95 \% \mathrm{Cl})$ & 1.17 (1.00 to 1.37$)$ & $1.08(0.92$ to 1.26$)$ & 1.0 (Reference) & $1.15(1.00$ to 1.33$)$ & 1.17 (1.01 to 1.34$)$ & $1.00(0.95$ to 1.06$)$ \\
\hline
\end{tabular}

$\mathrm{HR}=$ hazard ratio, $\mathrm{Cl}=$ confidence interval.

†Vitamin D intake was defined as below (low) or above (high) $4.4 \mu \mathrm{g}$ per day reported dietary vitamin D intake.

łHazard ratios $(95 \% \mathrm{Cl})$ were determined in Cox proportional hazard analysis. Adjusted hazard models included age, total energy, retinol, alcohol

intake, vitamin D intake, BMI, height, nulliparity, educational level, physical activity, smoking status, calcium supplementation, previous fracture of any type before baseline, and Charlson's comorbidity index.

covariates such as nulliparity, smoking, socioeconomic status, physical activity, nutrients other than calcium, educational level, and comorbidity, but residual confounding still remains a possible limitation. Dietary assessment methods are prone to a number of limitations, affecting both the precision and accuracy of the measurement. A food frequency questionnaire is used to assess the habitual intake of diet in larger studies, and a recent review concluded that it was a valid method for assessing dietary mineral intake, particularly for calcium. ${ }^{33}$ The food frequency questionnaire may overestimate calcium intake ${ }^{22}$ and the threshold of calcium intake detected in our analyses may therefore be somewhat exaggerated. Moreover, misclassification of study participants according to calcium intake may have introduced a conservative bias to our estimates of association. The observational study design precludes conclusions regarding causality. Our results might not apply to other people of different ethnic origins or to men.

\section{Strengths and weaknesses in relation to other studies}

The large size of this study enabled us to define a threshold of dietary calcium intake with better precision than in previous studies. The results from previous prospective cohort studies on the relation between dietary calcium intake and fracture risk are contradictory. British women older than 50 years had an increased risk of fractures (self reported five years after study entry) at calcium levels below $700 \mathrm{mg}$ compared with a reference level of $1200 \mathrm{mg} \cdot{ }^{34}$ Other large prospective cohort studies ${ }^{9521}$ and one meta-analysis ${ }^{7}$ reported no association between calcium intake and fracture risk.

Vitamin D enhances the renal conservation and intestinal absorption of calcium. ${ }^{1}$ Our results suggest that the optimal level for calcium intake for the prevention of osteoporotic fracture is higher when dietary vitamin $\mathrm{D}$ intake is low. This finding has not been shown ${ }^{21}$ or investigated ${ }^{35}$ in previous prospective studies but accords with findings in randomised co-supplementation trials. ${ }^{67}$ Circulating vitamin D levels are only to a lesser extent determined by the dietary intake of vitamin D. ${ }^{36-38}$ Nonetheless, dietary calcium intake was only associated with bone mineral density in women with serum vitamin $\mathrm{D}$ values less than 50 $\mathrm{nmol} / \mathrm{L}$ in the large NHANES III cohort. ${ }^{39}$

\section{Possible explanations and implications}

The present results may reflect a situation when a moderate intake of calcium combined with adequate intake of other micronutrients is sufficient to meet the structural and functional demands of the skeleton. High levels of intake did not further decrease the rate of fracture, and might even increase the rate of hip fractures, although this result should be cautiously interpreted. The finding might be explained by a reverse causation phenomenon; that is, women with a higher predisposition for osteoporosis may have deliberately increased their intake of calcium rich foods. We tried to avoid this bias by restricting the analysis to women with first fracture events. If it exists, this bias would probably have also been reflected in a higher rate of other types of fractures, not only hip fractures. Furthermore, few participants had knowledge of their bone mineral density (which could have influenced the dietary habits) since general screening of osteoporosis with bone mineral density scans does not exist in Sweden. Moreover, use of supplemental calcium has been associated with higher rates of hip fracture both in a cohort study ${ }^{40}$ and in randomised controlled trials. ${ }^{7841}$ The high calcium intake can reduce the enlargement of the appendicular bones that generally occurs with ageing as a mechanical compensation for a decline in bone mineral density. ${ }^{8}$ Furthermore, high calcium doses slow bone turnover and also reduce the number of active bone remodelling sites. ${ }^{42}$ This situation can lead to a delay of bone repair caused by fatigue, and thus increase the 


\section{WHAT IS ALREADY KNOWN ON THIS TOPIC}

Meta-analyses of randomised trials have found that supplemental calcium does not reduce the risk of fracture in community dwelling women

Meta-analyses of previous cohort studies have not established a reduction in fracture or osteoporosis risk with increasing calcium intake

Dietary nutrient estimates are imprecise, and large studies are therefore needed to detect thresholds in risk of fracture and osteoporosis

\section{WHAT THIS STUDY ADDS}

Dietary calcium intakes below approximately $700 \mathrm{mg}$ per day in women were associated with an increased risk of hip fracture, any fracture, and of osteoporosis

The highest reported calcium intake did not further reduce the risk of fractures of any type, or of osteoporosis, but was associated with a higher rate of hip fracture

risk of fractures independent of bone mineral density. ${ }^{42}$ The two dimensional DXA measurement precluded us from accurately determining associations between calcium intake and bone size, and specific associations with cortical and trabecular bone. ${ }^{43}$

Our observational data suggest that in the prevention of osteoporotic fractures emphasis should be placed on individuals with a low intake of calcium rather than increasing the intake of those already consuming satisfactory amounts, as previously argued by Prentice. ${ }^{44}$ Further research is needed-for instance, a randomised study with a factorial design that considers low baseline levels of calcium in combination with calcium supplements.

\section{Conclusions}

Incremental increases in calcium intake above the level corresponding to the first quintile of our female population were not associated with a further reduction of osteoporotic fracture rate.

Contributors: KM and EW designed the study, analysed and interpreted the data, and drafted the manuscript. AW contributed to the study design analysis and interpretation of the data, and writing of the manuscript. LB, $\mathrm{HMa}, \mathrm{HM}$, and RG interpreted the data and made significant contributions to drafts of the manuscript. All authors had full access to all data (including statistical reports and tables) in the study and take responsibility for the integrity of the data and the accuracy of the data analysis. EW and KM are guarantors.

Funding: Supported by the Swedish Research Council, grant numbers 2008-2202 and 2009-6281. The funding source was not involved in the design, conduct or interpretation of the study, or in the writing of the submitted work.

Competing interests: All authors have completed the Unified Competing Interest form at www.icmje.org/coi_disclosure.pdf (available on request from the corresponding author) and declare: no support from any organisation for the submitted work; no financial relationships with any organisations that might have an interest in the submitted work in the previous three years; no other relationships or activities that could appear to have influenced the submitted work.

Ethical approval: The study was approved by the regional ethics committees at Uppsala University, Uppsala, and Karolinska Institutet, Stockholm, Sweden, and all participants gave their informed consent. Data sharing: No additional data available.

1 Cashman KD. Diet, nutrition, and bone health. / Nutr 2007;137(suppl 11):2507-12S.

2 NHS Choices. Vitamins and minerals: calcium. www.nhs.uk/ conditions/vitamins-minerals/pages/calcium.aspx
3 Anonymous. Nordic nutrition recommendations 2004. Integrating nutrition and physical activity. 4th ed. Nordic Council of Ministers, 2004.

4 Yates AA, Schlicker SA, Suitor CW. Dietary reference intakes: the new basis for recommendations for calcium and related nutrients, $B$ vitamins, and choline. I Am Diet Assoc 1998;98:699-706.

5 Department of Health and Ageing (Australia), National Health and Medical Research Council (Australia), Ministry of Health (New Zealand). Nutrient reference values for Australia and New Zealand, including recommended dietary intakes. 2006. www.nhmrc.gov.au/ _files_nhmrc/file/publications/synopses/n35.pdf

6 Tang BM, Eslick GD, Nowson C, Smith C, Bensoussan A. Use of calcium or calcium in combination with vitamin $D$ supplementation to prevent fractures and bone loss in people aged 50 years and older: a meta-analysis. Lancet 2007;370:657-66.

7 Bischoff-Ferrari HA, Dawson-Hughes B, Baron JA, Burckhardt P, Li R, Spiegelman D, et al. Calcium intake and hip fracture risk in men and women: a meta-analysis of prospective cohort studies and randomized controlled trials. Am J Clin Nutr 2007;86:1780-90.

8 Reid IR, Bolland MJ, Grey A. Effect of calcium supplementation on hip fractures. Osteoporos Int 2008;19:1119-23.

9 Cumming RG, Nevitt MC. Calcium for prevention of osteoporotic fractures in postmenopausal women. J Bone Mineral Res 1997;12:1321-9.

10 Xu L, McElduff P, D’Este C, Attia J. Does dietary calcium have a protective effect on bone fractures in women? A meta-analysis of observational studies. Br J Nutr 2004;91:625-34.

11 Larsson SC, Bergkvist L, Wolk A. Long-term dietary calcium intake and breast cancer risk in a prospective cohort of women. Am J Clin Nutr 2009;89:277-82.

12 Calltorp J, Adami HO, Astrom H, Fryklund L, Rossner S, Trolle Y, et al. Country profile: Sweden. Lancet 1996;347:587-94.

13 Gedeborg R, Engquist H, Berglund L, Michaelsson K. Identification of incident injuries in hospital discharge registers. Epidemiology 2008;19:860-7.

14 Kanis JA. Assessment of fracture risk and its application to screening for postmenopausal osteoporosis: synopsis of a WHO report. WHO Study Group. Osteoporos Int 1994;4:368-81.

15 Melhus H, Snellman G, Gedeborg R, Byberg L, Berglund L, Mallmin H, et al. Plasma 25-hydroxyvitamin D levels and fracture risk in a community-based cohort of elderly men in Sweden. J Clin Endocrinol Metab 2010;95:2637-45.

16 Larsson SC, Bergkvist L, Wolk A. Long-term meat intake and risk of breast cancer by oestrogen and progesterone receptor status in a cohort of Swedish women. Eur J Cancer 2009;45:3042-6.

17 Larsson SC, Bergkvist L, Wolk A. Conjugated linoleic acid intake and breast cancer risk in a prospective cohort of Swedish women. Am J Clin Nutr 2009;90:556-60.

18 Bergström L, Kylberg E, Hagman U, Erikson H, Bruce Å. The food composition database KOST: the National Administration's information system for nutritive values of food. [Swedish]. Vår Föda 1991;43:439-47.

19 Willett WC, Howe GR, Kushi LH. Adjustment for total energy intake in epidemiologic studies. Am J Clin Nutr 1997;65(suppl 4):1220-8S.

20 Hu FB, Stampfer MJ, Rimm E, Ascherio A, Rosner BA, Spiegelman D, et al. Dietary fat and coronary heart disease: a comparison of approaches for adjusting for total energy intake and modeling repeated dietary measurements. Am J Epidemiol 1999;149:531-40.

21 Michaëlsson K, Melhus H, Bellocco R, Wolk A. Dietary calcium and vitamin $\mathrm{D}$ intake in relation to osteoporotic fracture risk. Bone 2003;32:694-703.

22 Messerer M, Johansson SE, Wolk A. The validity of questionnairebased micronutrient intake estimates is increased by including dietary supplement use in Swedish men. J Nutr 2004;134:1800-5.

23 Orsini N, Bellocco R, Bottai M, Hagstromer M, Sjostrom M, Pagano M et al. Validity of self-reported total physical activity questionnaire among older women. Eur J Epidemiol 2008;23:661-7.

24 Charlson ME, Pompei P, Ales KL, MacKenzie CR. A new method of classifying prognostic comorbidity in longitudinal studies: development and validation. J Chronic Dis 1987;40:373-83.

25 Quan H, Sundararajan V, Halfon P, Fong A, Burnand B, Luthi J, et al. Coding algorithms for defining comorbidities in ICD-9-CM and ICD-10 administrative data. Med Care 2005;43:1130-9.

26 Cleves M. Analysis of multiple failure-time survival data. 2009. www. stata.com/support/faqs/stat/stmfail.html

27 Kaaks R, Ferrari P, Ciampi A, Plummer M, Riboli E. Uses and limitations of statistical accounting for random error correlations, in the validation of dietary questionnaire assessments. Public Health Nutr 2002;5:969-76.

28 Stata Corporation. Stata reference manual, release 11. Stata Press, 2009.

29 Bolland MJ, Avenell A, Baron JA, Grey A, MacLennan GS, Gamble GD, et al. Effect of calcium supplements on risk of myocardial infarction and cardiovascular events: meta-analysis. BMJ;341:c3691. 
30 Sennerby U, Melhus H, Gedeborg R, Byberg L, Garmo H, Ahlbom A, et al. Cardiovascular diseases and risk of hip fracture. JAMA 2009;302:1666-73.

31 Fine J, Gray R. A proportional hazards model for the subdistribution of a competing risk. J Am Stat Assoc 1999;94:496-509.

32 Lin DY. Non-parametric inference for cumulative incidence functions in competing risks studies. Stat Med 1997;16:901-10.

33 Serra-Majem L, Pfrimer K, Doreste-Alonso J, Ribas-Barba L, Sanchez-Villegas A, Ortiz-Andrellucchi A, et al. Dietary assessment methods for intakes of iron, calcium, selenium, zinc and iodine. $\mathrm{Br}$ Nutr 2009;102 (suppl 1):38-55S.

34 Key TJ, Appleby PN, Spencer EA, Roddam AW, Neale RE, Allen NE. Calcium, diet and fracture risk: a prospective study of 1898 incident fractures among 34696 British women and men. Public Health Nutr 2007;10:1314-20.

35 Feskanich D, Willett WC, Colditz GA. Calcium, vitamin D, milk consumption, and hip fractures: a prospective study among postmenopausal women. Am J Clin Nutr 2003;77:504-11.

36 Burgaz A, Åkesson A, Öster A, Michaëlsson K, Wolk A. Associations of diet, supplement use, and ultraviolet $B$ radiation exposure with vitamin D status in Swedish women during winter. Am J Clin Nutr 2007;86:1399-404.

37 Burgaz A, Åkesson A, Michaëlsson K, Wolk A. 25-hydroxyvitamin D accumulation during summer in elderly women at latitude $60^{\circ} \mathrm{N}$ : J Int Med 2009;266:476-83.
38 Snellman G, Melhus H, Gedeborg R, Olofsson S, Wolk A, Pedersen NL, et al. Seasonal genetic influence on serum 25hydroxyvitamin D levels: a twin study. PLoS ONE 2009;4:e7747.

39 Bischoff-Ferrari HA, Kiel DP, Dawson-Hughes B, Orav JE, Li R, Spiegelman D, et al. Dietary calcium and serum 25-hydroxyvitamin D status in relation to BMD among U.S. adults. J Bone Mineral Res 2009;24:935-42.

40 Cumming RG, Cummings SR, Nevitt MC, Scott J, Ensrud KE, Vogt TM, et al. Calcium intake and fracture risk: results from the study of osteoporotic fractures. Am J Epidemiol 1997;145:926-34.

41 Reid IR, Mason B, Horne A, Ames R, Reid HE, Bava U, et al. Randomized controlled trial of calcium in healthy older women. Am J Med 2006;119:777-85.

42 Kanis JA, Passmore R. Calcium supplementation of the diet-II. BMJ 1989;298:205-8.

43 Griffith JF, Engelke K, Genant HK. Looking beyond bone mineral density: imaging assessment of bone quality. Ann N Y Acad Sci 2010;1192:45-56.

44 Prentice A. Diet, nutrition and the prevention of osteoporosis. Public Health Nutr 2004;7:227-43.

Accepted: 28 February 2011 